\title{
Implications of concepts of consciousness for understanding pain behaviour and the definition of pain
}

\author{
Kenneth D Craig PhD
}

\author{
KD Craig. \\ Implications of concepts of consciousness for understanding \\ pain behaviour and the definition of pain. \\ Pain Res Manage 1997;2(2):111-117.
}

Judgements of the nature and severity of pain others may be experiencing are heavily influenced by an observer's preconceptions about the nature of the experience. Our personal sense of conscious experience dictates a search for consciousness characterized by the state of awareness found in competent adults, including constructive memories and thoughts, images and feelings. People incapable of verbally articulating experiences akin to those reported by competent older children and adults are at risk of having other evidence of pain denied, minimized or ignored. Despite substantial behavioural evidence for pain in the neonate and infant, and findings indicating destructive immediate and long term consequences if pain is not controlled, pain in infants and children often continues to be discounted. An alternative perspective on infant consciousness of pain focusing upon sensory and emotional components is presented. The current prominent definition of pain supports the prejudice favouring adult conceptions of consciousness by emphasizing the importance of self-report in assessing pain. Explanatory notes accompanying this definition also perpetrate the misguided belief that the experience of pain emerges as a product of early life experiences. The case for using nonverbal as well as verbal expression in the process of inferring states of pain is presented. As well, the proposition is supported that there should be explicit recognition that the experience of pain is an inherent quality of life present in all viable newborns, with the nature of the experience and its expression changing in the course of maturation and as a result of exposure to life experiences related to tissue injury.

Key Words: Consciousness, Infancy, Pain definition

\section{Implications des concepts de conscience pour comprendre les comportements liés à la douleur et la définition de la douleur}

RÉSUMÉ : Les jugements sur la nature et l'intensité de la douleur dont les autres peuvent faire l'expérience sont fortement influencés par les idées préconçues d'un observateur sur la nature de l'expérience. Notre sens personnel d'une expérience consciente dicte une recherche de la conscience caractérisée par la prise de conscience que l'on trouve chez les adultes compétents, incluant la construction de la pensée et du souvenir, d'images et de sentiments. Les personnes incapables d'exprimer verbalement leurs expériences analogues à celles rapportées par des enfants compétents plus âgés et des adultes courent le risque que les autres ne remarquent pas leur douleur, la minimisent ou l'ignorent. En dépit de preuves substantielles que la douleur existe chez le nouveau-né et le nourrisson, et des études qui démontrent qu'une douleur non maîtrisée a des conséquences désastreuses à court et à long terme, la douleur chez les bambins et les enfants reste souvent ignorée. Une autre perspective de la conscience de la douleur chez le nourrisson qui se concentre sur les composantes sensorielles et émotionnelles est présentée. La définition sur la douleur qui prévaut actuellement est préjudiciable aux nourrissons puisqu'elle favorise les conceptions de la conscience chez l'adulte en insistant sur l'importance pour celui-ci de signaler lui-même qu'il éprouve une douleur afin que cette dernière puisse être évaluée. Les explications qui accompagnent cette définition perpétuent également de façon abusive la croyance que l'expérience de la douleur survient comme un produit des expériences survenues dans la vie précoce. La proposition d'utilisation de l'expression verbale et non verbale dans le processus de déduction des états de la douleur est présentée. De même, les auteurs favorisent l'hypothèse qu'il faut reconnaître explicitement que l'expérience de la douleur est une qualité inhérente à la vie présente chez tous les nouveau-nés viables, et que la nature de l'expérience et de son expression change au fur et à mesure de leur maturation et résulte de leur exposition aux expériences de la vie liées à une atteinte des tissus.

This paper is based on a presentation at a workshop on consciousness, pain and behaviour at the annual meeting of the Canadian Pain Society, May 23, 1997, at Niagara-on-the-Lake, Ontario

Faculty of Graduate Studies, University of British Columbia, Vancouver, British Columbia

Correspondence: Dr KD Craig, Faculty of Graduate Studies, University of British Columbia, 180-6371 Crescent Road, Vancouver, British Columbia V6T 1Z2. Telephone 604-822-3380,fax604-822-5802, e-mail kcraig@mercury.ubc.ca

Received for publication May 23, 1997. Accepted June 30, 1997 
A $\mathrm{s}$ with all social judgements, attempts to understand the pain others may be experiencing depend upon effective use of both verbal and nonverbal information provided by the suffering individual. But, again as in all social encounters, the expectations and conceptual biases of observers heavily constrain their use of this information. This report addresses widely held preconceptions about the nature of the subjective experience of pain that diminish the capacity to empathize with people incapable of verbally articulating their pain and lead to unrealistic biases favouring self-report strategies for pain assessment.

Of prime interest are commonplace concepts concerning the role of consciousness implicit in concepts of pain. It appears that, unless a person is capable of qualities of conscious experience akin to those observed in competent older children and adults able to selfreport their distress, observers find it easy to discount, deny or ignore the existence, severity or importance of nonverbal expressions of distress. This bias, leading to greater sympathy for the plight of those capable of adult levels of conscious awareness, is reflected in the current definition of pain promulgated by the International Association for the Study of Pain (IASP) (1), particularly in its emphasis upon self-report as the vehicle for accessing the subjective experience of the individual experiencing pain. While the IASP definition of pain has many admirable features that have led to important advances in knowledge and pain management (2), the limitations are substantial and derive from an unreasonable perspective on consciousness; hence, the definition demands clarification.

The emphasis here will be on human neonates and infants, given recent concerted efforts to understand their experience of pain, in addition to a growing appreciation of the importance of effective management, if destructive long term consequences are to be avoided (3-5). One could focus on the effect of these biases on our understanding and assessment of pain in a diverse group of human conditions associated with limitations in the capacity to self-report pain, including developmental disabilities, brain injuries, brain diseases leading to cognitive dementias, drug-induced alterations of consciousness, language deficits and voluntary mutism, as well as on concepts of pain in nonhuman species. However, the complexities of the questions that would arise, and, in some instances, a limited empirical base, necessitate a limit to observations made here. Following a description of behavioural evidence for the inference that newborns and infants experience pain during invasive procedures, concepts of consciousness that have led to unrealistic emphases in the definition of pain will be examined.

\section{PAIN BEHAVIOUR}

Scientific advances follow from detailed observation of the phenomena of interest, guided by careful theoretical awareness. Twenty years ago, an interest in the processes whereby socialization in the family and culture lead to the dramatic individual differences observed in the expression of pain (6) led me to a review of pain in children (7). Probably the most striking report in the literature at that time was Eland and Anderson's 1977 paper (8) on the shocking undertreatment of pain in infants and children. While there is evidence of improvements in the use of analgesics with young children and improvements in the quality of care, concern remains a focus of current reviews (9) because there is a continued reluctance among practitioners (10-12) and parents (13) to control pain, despite strong evidence that analgesics and nonpharmacological approaches to pain control are both effective and safe.

Applying the conviction that one can best understand phenomena through careful observation, we initiated a series of studies in clinical settings where children's reactions to invasive procedures can be readily observed. In our first study (14), the detailed behavioural observation procedures provided strong evidence of pain in the children's behaviour, as well as systematic variation associated with motor and cognitive development, and differences in how mothers coped with their children's distress contingent upon the infant's age. These observations made it obvious that we had a viable approach to collecting valuable data. This, and subsequent studies described below, made claims for insensitivity to painful events in very young children seem nonsensical and led to speculation of whether those making the assertion had actually engaged in careful observation or, if they had, what preconceptions they held allowed them to deny or distort the blatant evidence available to them (15).

Because facial activity is extraordinarily important in communications among people of all ages, and faces are highly dynamic and disclose considerable information about subjective states even in newborn children $(16,17)$, facial activity became the prime focus of the research program. The major measurement tool that emerged, the Neonatal Facial Coding Scale $(18,19)$, provided convincing demonstrations of the following.

There is a stereotypic pattern of facial activity during invasive events in very young children that differentiates painful and nonaversive states $(18,20,21)$.

The Neonatal Facial Coding Scale captures those facial actions needed to assess pain throughout infancy $(22,23)$.

There is consistency through life in the pattern of display observed, with some variation $(23,24)$.

Adults have little difficulty identifying the display as indicative of pain and use facial displays effectively in their judgements of pain severity (25).

Central nervous system states, sleep/waking behavioural states in particular, modulate the display (18).

The pattern is observable in neonates born prematurely, with variations in the vigour of the display associated with the gestational age of the child $(24,26)$.

The reaction diminishes as would be expected when systemic analgesics (unpublished data) or topical analgesics (27) are used clinically.

The facial display can be effectively used clinically to assess pain (28).

Notwithstanding accumulating evidence for pain in infants and how it should be assessed (29), all conclusions that another person, infant or not, is experiencing pain are inferential. This shifts the emphasis from the subjective experience of the person - who may or may not be in pain and who may or may not provide conspicuous evidence to this effect - to the subjective judgements of the observer. Explanations of attributions of pain to another person require communication models of pain. These address the mechanisms whereby the experience is encoded in verbal and nonverbal behaviour and the varying sensitivities and decision strategies health practitioners and others display and use when interpreting the suffering 
person's subjective distress. Prkachin and Craig (17) used this perspective to describe the use of facial activity to judge the pain of others, and Craig et al (30) used this model to examine concepts of children's pain that are unduly narrow and that represent barriers to effective care if they are restricted to internal subjective states and their biological substrates. To appreciate the care provided to children, one must also look at how children display pain, adult's sensitivities to this information, and sources of error and biases on these judgements. It is clear that judgements of pain not only reflect evidence of tissue damage or stress and relevant contextual information, but also can be biased by characteristics of the suffering person ordinarily considered irrelevant to factors that actually influence the pain. For example, Hadjistavropoulos and colleagues (31) found that physicians characterized unattractive people as in greater pain and in need of more care than attractive people. The bias has some partial, but insufficient, foundation in that unattractive people were more likely to engage in passive coping, a less effective strategy for controlling pain, although this is not enough to account for the stereotype $(32,33)$.

The program of research described above emphasized detailed behavioural description of infant behaviour, by using standard scientific criteria for demonstrating the viability, importance and usefulness of a construct. However, it also was clear that we (29) were attempting to demonstrate the importance of recognizing that infants are capable of the experience of pain. Our rhetoric and colleagues' questions often seemed attentive to whether the evidence legitimizes the conclusion that these infants experience pain. To the extent to which experience implies consciousness, we must address the nature of consciousness or the phenomenology of pain from the perspective of the sufferer. With children the questions often focus on how qualities of consciousness emerge in the course of infant and child development.

\section{CONSCIOUSNESS AS AN ATTRIBUTE OF OTHER PEOPLE}

Similar to the manner in which we know pain, people know consciousness through personal experience but have great difficulty defining it in the abstract or describing its essential elements. From my adult and human perspective, it is a state of experience in which events are attended to and addressed at a level of focal awareness and in the thoughts of the individual. It usually comprises a dynamic flow of feelings, images and thoughts that are often turbulent and not readily reduced to descriptive language. It involves the acquisition and use of knowledge, a 'cool' side, inextricably and invariably bound to motives and emotions that organize, occasionally disrupt and invariably give meaning to events, the more irrational, less predictable and 'heated' side. We experience, as components of our consciousness, the impact of external events on sensory organs (exteroceptive sensation), internal biological states (interoceptive sensation) and memories brought to consciousness that introduce order to perceptual experience. A complex amalgam of sensations, feelings, memories and thoughts is at the centre of our conscious experience at any moment in time.

I propose, as have others $(34,35)$, that there are different forms of consciousness. In the interest of simplicity, let us consider only two possibilities, undoubtedly collapsing others. There seems to be some level of primary consciousness whereby the individual is aware of events and properties of the surrounding world. This level of awareness is perhaps most easily seen in the newborn child and young infant whose gaze constantly explores and fixates during states of wakefulness. Parents find those occasions when the newborn fixates upon them to be particularly satisfying, if not thrilling. A higher order of consciousness would entail recognition by a thinking person of his or her own acts or affections, with reference to the past, present and future. This self-awareness seems to characterize mature children and adults best and to be the most prominent characteristic of what adults recognize as consciousness. With it we are able to plan and construct our environments. This capacity to think and plan only slowly emerges in the course of growing up.

For centuries, it has been the capacity to think that has defined consciousness. The 17th century philosopher Descartes stated it aptly with his dictum, cogito, ergo sum - I think, therefore I am. Most people have endorsed the proposition that this higher level of self-awareness is a sine qua non of consciousness. For those subscribing to this narrow view, a corollary would be that until this form of consciousness emerges, person-hood does not exist. It seems that one could construe those deficient in this higher order consciousness as a complex amalgam of biological organ systems capable of little more than reflexive action and, perhaps in more compassionate terms, with genetic programs that will ultimately permit conscious experience to manifest itself. Presumably until this takes place, there can be little suffering in the sense that the individual cannot evaluate or recognize the significance of events. But this narrow definition of consciousness begs for definition of the nature of thinking and contributes to the risk that those incapable of verbally articulating their thoughts will be seen as neither capable of thought nor in possession of a capacity for consciousness. The trap is to assume that the absence of a competent adult's capabilities for experience and communication means there is no possibility of consciousness.

Denial of a capacity for conscious experience is implicit in assertions that neonates and infants are insensitive to pain. Despite extensive literature on pain in nonhuman species (36), one also can find similar assertions referring to infrahuman species. Carruthers (37) wrote of animals in the prestigious Journal of Philosophy that, "since their experiences, including their pains, are nonconscious ones, their pains are of no immediate moral concern. Indeed, since all of the mental states of brutes are nonconscious, their injuries are lacking even in indirect moral concern". Coren (38) notes that these beliefs found full flowering in Descartes's attempts to describe dogs as mechanical or complex automatons. For Descartes, because dogs did not think, they were not. A thorough investigation of animal consciousness and pain based on studies of the history and philosophy of science can be found in Rollin (39). That work concludes that animals experience pain. While this analysis has lapsed into an account of the capabilities of nonhuman species, it can be noted that if creatures are construed as nonconscious and incapable of pain, there is the potential for legitimizing nonhumane conduct.

Our tendency to use our personal experience as a model for interpreting the experience of others seems to limit the capacity to appreciate existing differences in consciousness. Evidence for dramatic differences between the cognitive and expressive capabilities of neonates, infants, older children and adults can be readily generated and should be used to formulate accounts of the likely experiences 
of people during different stages of the lifespan. The tripartite characterization of painful experience - referring to its sensorydiscriminative, affective-motivational and cognitive-evaluative components - devised by Melzack and Casey (40) provides a basis for speculation on the nature of the infant's experience of pain (15). At birth, sensory systems for nociception are well developed, and the vigour of newborns' reactions conveys evidence of tremendous affective distress. The neonate's capacity to attach meaning to situations is present but minimal relative to later development, as reflected, for example, in a child's preferences for his or her mother over other women. One also might interpret the vigorous behavioural reaction to an invasive procedure not only as pain but also as reflecting a sense of danger or apprehension concerning physical threat. It seems that, in the very young child, sensory and emotional qualities of pain must dominate. If there were a total absence of memories or no capacity to anticipate the future, the immediacy of events would be everything. As adults, we might consider this to be a primitive form of consciousness dominated by hedonic qualities of pleasure and distress, with painful events probably overwhelming in the absence of a capacity to recognize their meaning or to plan some form of escape.

It does not appear difficult for adults to conceptualize children as different in their experience of pain. Schechter and Allen (41) provide evidence of a linear correlation between the age of children and physician's beliefs that they can experience pain in a manner similar to that of adults, with surgeons, as compared with pediatricians, less willing to attribute adult capabilities to the children or to use postoperative analgesics. Age is acknowledged by pediatric nurses as a factor that they consider when making decisions about pain management (42). This has an impact on practice because analgesics are used more regularly in pediatric than in neonatal intensive care units (43).

Absence in the infant of the cognitive faculties that adults and older children employ to understand and give meaning to painful events, as well as deficiencies in the capacity to articulate what is wrong to others, seems to make it easy to assert that infants do not experience pain or to dehumanize infants as little more than bundles of biological reflexes. Derbyshire (44), for example, notes, "unless there is the possibility that the neonate has a conscious appreciation of pain, then any responses to noxious stimulation are essentially reflex responses, of the same quality as any responses prior to development of the cerebral cortex". The infant does not seem to know what is happening, which, after all, is the essence of what we characterize as a subjective experience. An alternative perspective is that adults who do not understand what is happening to them, who do not have a capacity to see that certain noxious events will end or who are deficient in the capacity to let others know about their states of distress, would be likely to experience sheer terror. Perhaps that is the more reasonable way to characterize the subjective experience of pain in the infant and young child.

Studies of the biological regulation of levels of consciousness that do not depend on high levels of cortical input are available and provide insight into the probable nature of the neonate and infants' experience of pain. Apprehension of danger and threats to survival would be expected early in the course of evolutionary development of biological systems. Similarly, a capacity to remember environments that signal such threats would be adaptive. An aversive mem- ory system would be one of the most primitive, and one can readily demonstrate long-lasting memories of aversive events in subhuman species. One does not need an evolved state of consciousness for pain to have a long-lasting cognitive and behavioural impact. In fact, as LeDoux (45) observed, it is parsimonious to not require a high level of consciousness awareness in theoretical models of memory for aversive events.

LeDoux's (45) account of the neurobiological systems regulating fear provides an appreciation for the levels of consciousness to be observed in neonates and infants. If one defines consciousness in its least evolved form as focusing upon sensory information processing and associated emotional states, then, primarily, activity in the sensory thalamus and the amygdala are implicated. If the cognitive processing of higher states of self-awareness is available, then not only the sensory cortex is implicated but also processing in complex association areas of cortex in the frontal lobes or hippocampus must be involved (45). Even in competent adults there is survival value in a 'quick and dirty' subcortical pathway that allows immediate processing of sensory information to determine whether it is dangerous; that does not rely upon cortical processing; and that permits rapid response to danger. It is the thalamic input that provides these coarse representations. The sensory afferents rapidly arrive at the amygdala, whereas cortical input is slower because additional processing is required to distinguish among stimuli (45). The amygdala appears to provide the neural instantiation of the low level cognitive and emotional processes that would be characterized as the appraisal of danger.

It is interesting that studies of infantile amnesia suggest that traumatic events as an infant (before the second or third year of life) are encoded as emotional memories rather than as explicit declarative memories and that they are not accessible to conscious experience, even though they can have a dramatic long term behavioural impact. This inaccessibility seems to be because the emotional memory system (operating through the amygdala) is operative at this time rather than the declarative memory system (operating through the hippocampus), which is not functional then (45).

If we abandon monolithic concepts of consciousness, dominated by our capacities as adults to be self-aware and to engage in foresight, we would recognize other capacities for consciousness, but that will not be easy. When confronted with puzzling events in the absence of a good theory to explain them, humans tend to anthropomorphize or engage in animistic thinking. Endowing the inanimate natural environment with spirits or adult human qualities is a commonplace propensity when phenomena are poorly understood. Dennet (46) described this endowment as conceivably an innate tendency. As a first approximation to explanation, and as a source of comfort because there is a presumption of understanding, the approach has some utility. But if the fit is inexact, inappropriate treatment might ensue. When confronted with the mysteries of the newborn child, it might make sense to look for adult consciousness. When not found, it may be possible to deny the importance of the child's experiences. What is needed is an account of different capabilities and competencies, not a denial of consciousness and associated subjective states.

A further metaphor deserves comment. It derives from the dominant role of the discipline of anesthesia in structuring our thinking about pain and analgesics. The goal of general anesthesia is to in- 
duce unconsciousness. Does this suppression of consciousness provide a good model or metaphor for understanding emerging consciousness in childhood or for infants who have not achieved the adult level of consciousness in which self-awareness is paramount? Smith (47) uses the metaphor directly in asserting, "a baby with an underdeveloped cortex and a deeply anesthetized patient both lack cortical activity, and both are unable to feel pain". As with many metaphors the match is incomplete in many respects. The neonate is too active and engaged with the external world to be compared with people experiencing drug-induced loss of consciousness. Thus, one must be able to consider different variations of consciousness.

It is also noteworthy that pain is an arousal-instigating event. Pain can be imposed during various levels of consciousness and have the impact of altering levels of consciousness and focusing attention. Pain can break through the sedating effects of analgesics. Perhaps some of the earliest states of self-awareness are instigated in the child by pain.

Finally, it should be noted that for some people there seems to have been functional value in construing the infant and young child as capable of little more than reflexive activity and incapable of the experience of pain. If dealing with an acutely ill child or engaged in life-threatening interventions, or if one fears the impact of interventions (for example, side effects such as toxicity or the respiratory suppression of the opioids), it may be adaptive to suspend beliefs in the consciousness of this infant or young child because then feelings of pity, compassion, sympathy or guilt become unnecessary. We now recognize that these concerns are spurious and can lead to failure to provide adequate treatment or to long term destructive consequences (3). The capacity to empathize or to be child-centred (able to take the perspective of the child) remains important, irrespective of the nature of one's interaction with the child (48). Cunningham (49) has addressed in broad terms how belief systems lead to doubts, denial and discounting of infant pain and resistance to changes in practice.

\section{ON THE DEFINITION OF PAIN}

In an editorial in Pain, Anand and Craig (2) recently questioned certain features of the IASP definition of pain - "an unpleasant sensory and emotional experience associated with actual or potential tissue damage, or described in terms of such damage" (1). The cognitive/evaluative parameters of pain are not specifically denoted, other than through reference to the capacity of the individual to describe the experience of pain in terms of tissue damage. The problems derive from the emphasis on the capacity to describe pain and the subsequent explanation of the definition where the IASP committee notes, "pain is always subjective. Each individual learns the application of the word through experiences related to injury in early life" (1).

In our editorial (2) we noted that there is much to be admired in the IASP definition and that it has served us well, but the definition and its explication have two major limitations that perpetuate failures to provide care for nonverbal humans adequately, with our focus again primarily upon newborns and infants. The IASP definition encourages an insistence upon self-report if one is to access the subjective experience of pain and it fosters the proposition that one must learn to experience pain.

Some critical commentary of our editorial was provided by Wall
(50), Merskey (51) and Derbyshire (44) in the same issue of Pain. We were provided with the Wall and Merskey reviews in advance, so were able to respond in print to their observations (52), but not so with the commentary by Derbyshire. His comments were broad to say the least. Cunningham (53) provided a rejoinder in Pain, noting that according to Derbyshire (44), our arguments compel us "to embrace the concepts of materialism, dualism, specificity theory, and metaphysical or 'supernatural' viewpoints, all discredited within the field of pain research". Cunningham (53) provided a critical perspective of philosophical limitations to Derbyshire's arguments. This is important because Derbyshire makes such claims as: "the authors are clearly motivated by a humanitarian desire to eliminate suffering. This is commendable. However, in this authors (sic) opinion their ideals are misdirected, their proposed redefinition of pain misconceived and their cavalier attitude to changing medical practice potentially dangerous"; and "they may also be encouraging neonatal surgeons and gynaecologists (sic) in the use of dangerous anesthetic procedures to alleviate pains which do not exist".

I initially wrote off his conclusions as irrelevant because they are so inconsistent with solid data, but I am now not so sure they can be ignored. Words are potent. They lead to action or inaction. They rationalize or justify behaviour one would otherwise consider harmful. Undertreatment of pain remains commonplace and those who perpetrate inadequate care do not need additional fuel.

I am pleased to say that Cunningham (53) concluded that, "Derbyshire is incorrect that, with their new definition of pain, Anand and Craig '...have too easily rejected over three decades of experimental research'. However, Derbyshire is correct 1) that acceptance of their proposal would profoundly affect the current understanding of pain in nonverbal humans and animals; 2) that a change in philosophical perspectives, rather than new scientific evidence, would be motivator of this change in the definition of pain; and 3) that the ethical implications of such a change would be far-reaching."

\section{PRIME CONCERNS WITH THE CURRENT DEFINITION OF PAIN}

\section{Role of nonverbal and verbal measures}

The role of nonverbal and verbal measures must be acknowledged as a source of information about another's pain. The focus upon subjective experience has led to a requirement for self-report although this does not necessarily follow. One could argue that the definition is of sufficient scope to allow any form of inferring subjective experience, but there has been an inordinate emphasis on self-report as a means of accessing subjective experience and other sources of information tend to be denigrated.

There are many examples in the research and practitioner literatures of the insistence on using self-report. One of the first and most powerful comes from Engel's classic paper (54): " 'Psychogenic' pain and the pain-prone patient" in the American Journal of Medicine: "as observers we cannot even recognize pain. Indeed, pain can only be experienced and for our information about pain we are totally dependent upon the report of the person experiencing it". Meinhart and McCaffery (55) state in their classic text on nursing approaches to pain assessment and management: "the patient's verbal report is the only way to determine the presence, intensity, and quality of pain...". 
Unquestionably, the careful use of well-designed self-report measures works well for articulate and credible older children and adults. Accurate, valid and useful information can be made available. But too frequently, stating that self-report is the gold standard for pain assessment simply allows the user to ignore the limitations of self-report as a source of inference (56). The limitations centre on the improbability of our being able to describe the complexities of the thoughts, images, feelings and sensations that comprise our phenomenal worlds, the inevitability that we will have to select certain qualities to report and the probability that what we end up reporting will reflect our judgement as to what is best for us. Thus, there are built-in response biases, and people are able to exaggerate, suppress or otherwise purposefully or unwittingly distort complaints of pain. If the observer, whether clinician, scientist, parent or other concerned person, is unaware of these, the 'gold standard' can be 'fool's gold'.

The large numbers of people who cannot report pain are a serious concern. Infants are an obvious example, but there are many other possibilities. Neurological and neuromuscular deficits, either inherited or acquired, handicap many people. Thus, among others, the insistence upon self-report further handicaps people with developmental delays and diseases leading to dementia or brain damage, as well as those challenged motorically who do not have a capacity to self-report on their experiences. There are other people, wholly intact biologically, who are without verbal or social skills or capabilities, such as people who do not speak the same language as the clinicians or scientists, or people who are electively mute. All nonhuman species have a similar handicap. It is inevitable that observers will use nonverbal modes of communication, as clinicians and animal scientists are well aware, and nonverbal communication is a fundamental component of effective social discourse (15). The insistence on self-report inevitably will give way to recognition that observers use and integrate many sources of information when assessing the distress of others $(17,30)$.

Explicit recognition that pain experience is an inherent quality of life present in all viable newborns

There should be explicit recognition that the experience of pain is an inherent quality of life present in all viable newborns, with the meaning of the experience changing in the course of maturation and exposure to life experiences related to tissue injury. Our second concern was with the proposition that pain needs to be learned through experience. Merskey (51) has argued that it is only the meaning of the term pain that is acquired or changed through experience, and agreed that there is good evidence for probable pain in the newborn. We agree with him except for the use of the term "probable". Our objection is to the ultracautious perspective on pain in the infant and child. There is as much reason to be equally sceptical about the self-report of pain in the adult. If the term 'probable' (or a related qualifier) is applied to the infant, it also should be used with older children and adults.

Unfortunately, the IASP definition supports other less satisfactory interpretations of the role of experience as a shaper of pain. Engel (54), in the seminal paper already discussed, states: "the capacity to experience pain in the first place develops from numerous peripherally induced experiences...". In a more recent example, Maurer and Maurer (57) assert their belief in the insensitivity to pain in the newborn, as follows: "compared to adults, babies have had the chance to learn few neuronal patterns, so fewer stimuli seem abnormal to them. Therefore they are less likely than adults to feel pain"; and "newborns have had even less time to learn neuronal patterns, so they are even less likely than the one month old to feel pain”. They add: “...a newborn baby does not feel hunger and is fairly insensitive to pain. He may sound as if he is being starved or crucified, but he does not feel that way. Rather he feels stressed by excessive stimulation - overstimulation, like a farmer visiting New York City". To be clear, the argument is not for Plato's perspective that we have innate ideas. Rather, it is an argument for recognition of a form of consciousness in which sensory and affective systems dominate in the first instance, with the impact of experience accruing over time.

There are increasing numbers of studies showing the long term formative impact of early experiences with pain (3). This certainly would be expected because mnemonic behaviour can be demonstrated easily during infancy (58). Taddio et al (59) showed that newborn males circumcised at birth displayed more distress on the occasion of their first immunization injection four months later than noncircumcised boys. Grunau and colleagues (4) found that infants born prematurely and spending substantial time in necessarily aversive neonatal intensive care unit environments were characterized during the preschool years by their parents as both relatively insensitive to pain and inclined to somaticize when in distress (60), response patterns that are not necessarily incompatible. Johnston and Stevens (61) demonstrated a similar potent impact of premature birth and early hospital experiences. As children grow older, opportunities to learn through direct experience are augmented by the social experiences of adult instruction and vicarious learning, such that experiences of pain come to reflect the unique family and cultural environments in which children grow up (6). While we now know more about the role of social contexts in the long term impact of early pain experiences, a great deal more needs to be learned.

To return to the definition of pain, it seems reasonable to replace the sentence "each individual learns the application of the word through experiences related to injury in early life" (1). This sentence again emphasizes self-report, neglecting the important emphasis of the definition on subjective experience and, perhaps unwittingly, supports the erroneous and destructive position that the neonate is not born with a capacity to experience pain but must learn it. A reasonable replacement sentence would be, "meaning is attached through experiences related to injury in early life".

\section{CONCLUSIONS}

Systemic problems in assumptions about pain in infants and children were not our concern when we began the studies reviewed here 15 years ago. But now it is clear that fundamental approaches to conceptualizing human experience - and consciousness in particular - are a source of neglect of pain in infants, children, and other groups of humans and nonhuman species mentioned above. The existing definition of pain perpetuates some of the unfortunate thinking. Revision seems necessary.

ACKNOWLEDGEMENTS: Support of the Social Sciences and Humanities Research Council of Canada and the Medical Research Council of Canada in the preparation of this paper are gratefully acknowledged. 


\section{REFERENCES}

1. Merskey H, Bogduk N. Classification of Chronic Pain: Description of Chronic Pain Syndromes and Definitions of Pain Terms. Seattle: IASP Press, 1994.

2. Anand KJS, Craig KD. New perspectives on the definition of pain. Pain 1996;67:3-6.

3. Anand KJS. Long-term effects of pain in neonates and infants. In: Jensen TS, Champion DG, eds. Proceedings of the VIIIth World Congress on Pain: Pain Research and Clinical Management. Seattle: IASP Press. (In press)

4. Grunau RVE, Whitfield MF, Petrie JH. Pain sensitivity and temperament in extremely low-birth-weight premature toddlers and preterm and full-term controls. Pain 1994;58:341-6.

5. Taddio A, Katz J, Ilersich AL, Koren G. Effect of neonatal circumcision on pain response during subsequent routine vaccination. Lancet 1997;349:291-2.

6. Craig KD. Social modeling influences: Pain in context. In: Sternbach RA ed. The Psychology of Pain, 2nd edn. New York: Raven Press, 1986.

7. Craig KD. Ontogenetic and cultural determinants of the expression of pain in man. In: Kosterlitz HW, Terenius LY, eds. Pain and Society. Dahlem Konferenzen. Deerfield Beach: Basal, 1979:39-52.

8. Eland JM, Anderson JE. The experience of pain in children. In: Jacox A, ed. Pain: A Sourcebook for Nurses and Other Health Professionals. Boston: Little, Brown and Co, 1977:453-73.

9. Walco GA, Cassidy RC, Schechter NL. Pain, hurt, and harm. The ethics of pain control in infants and children, N Engl J Med 1994;331:541-4

10. Fernandez CV, Rees E. Pain management in Canadian level 3 neonatal intensive care units. Can Med Assoc J 1994;150:499-504.

11. Fletcher AB. Pain in the neonate. N Engl J Med 1987;317:1347-8.

12. McLaughlin CR, Hull JG, Edwards WH, Cramer CP, Dewey WL. Neonatal pain: A comprehensive survey of attitudes and practices. J Pain Symptom Manage 1993;8:7-16.

13. Finley CA, McGrath PJ, Forward SP, McNeill C, Fitzgerald P. Parents' management of children's pain following major surgery. Pain 1996;64:83-7.

14. Craig KD, McMahon RJ, Morison JD, Zaskow C. Developmental changes in infant pain expression during immunization injections. Soc Sci Med 1984;19:1331-7.

15. Craig KD, Grunau RVE. Neonatal pain perception and behavioural measurement. In: Anand KJS, McGrath PJ, eds. Neonatal Pain and Distress. Amsterdam: Elsevier, 1993:67-105.

16. Craig KD, Prkachin KM, Grunau RVE. The facial expression of pain. In: Turk DC, Melzack R, eds. Handbook of Pain Assessment. New York: Guilford, 1992:225-74.

17. Prkachin KM, Craig KD. Expressing pain: The communication and interpretation of facial pain signals. J Nonverbal Behaviour 1995; 19:191-205

18. Grunau RVE, Craig KD. Pain expression in neonates. Facial action and cry. Pain 1987;28:395-410.

19. Grunau RVE, Craig KD. Facial activity as a measure of neonatal pain expression. In: Tyler DC, Krane EJ, eds. Advances in Pain Research and Therapy. New York: Raven Press, 1990:147-55.

20. Grunau RVE, Johnston CC, Craig KD. Neonatal facial and cry responses to invasive and non-invasive procedures. Pain 1990;42:95-305.

21. Stevens B, Johnston CC, Horton L. Factors that influence the behavioural responses of premature infants. Pain 1994;59:101-9.

22. Craig KD, Hadjistavropoulos HD, Grunau RVE, Whitfield MF A comparison of two measures of facial activity during pain in the newborn child. J Pediatr Psychol 1994;19:305-18.

23. Lilley CM, Craig KD, Grunau RVE. The expression of pain in infants and toddlers: Developmental changes in facial activity. Pain. (In press)

24. Johnston CC, Stevens B, Craig KD, Grunau RVE. Developmental changes in pain expression in premature, fullterm, two, and four month-old infants. Pain 1994;52:201-99.

25. Hadjistavropoulos HD, Craig KD, Grunau RVE, Johnston CC. Judging pain in newborns: Facial and cry determinants. J Pediatr Psychol 1994;19:305-18.

26. Craig KD, Whitfield MF, Grunau RVE, Linton J, Hadjistavropoulos HD. Pain in the preterm neonate: Behavioural and physiological indices. Pain 1993;52:287-99.

27. Taddio A, Stevens B, Craig KD, et al. Efficacy and safety of lidocaine-prilocaine cream for pain during circumcision. N Engl J Med 1997;336:1197-201

28. Stevens B, Johnston CC, Petryshen P, Taddio A. Premature Infant Pain Profile: Development and initial validation. Clin J Pain 1996;12:13-22.
29. Craig KD. Facial measures of pain in infants and children. In: McGrath PJ, Finley A, eds. Measurement of Pain in Infants and Children. Seattle: IASP Press. (In press)

30. Craig KD, Lilley CM, Gilbert CA. Social barriers to optimal pain management in infants and children. Clin J Pain 1996;17:247-59.

31. Hadjistavropoulos HD, Ross M, von Baeyer C. Are physician's ratings of pain affected by patients' physical attractiveness. Soc Sci Med 1990;31:69-72

32. Hadjistavropoulos T, McMurtry B, Craig KD. Beautiful faces in pain: Biases and accuracy in the perception of pain. Psychol Health 1996;11:411-20.

33. Hadjistavropoulos T, Hadjistavropoulos HD, Craig KD. Appearance-based information about coping with pain: Valid or biased? Soc Sci Med 1995;40:537-43.

34. Chapman CR, Nakamura Y. Hypnotic analgesia: A constructivist framework. Int J Exp Clin Hypnosis. (In press)

35. Kihlstrom JF. The psychological unconscious and self. In: Bock GR, Marsh J, eds. Experimental and Theoretical Studies of Consciousness. Chichester: Wiley, 1993:147-67.

36. Dubner R. Methods of assessing pain in animals. In: Wall PD, Melzack $\mathrm{R}$, eds. Textbook of Pain. Edinburgh: Churchill Livingstone, 1994:293-302.

37. Carruthers P. Brute experience. J Philosophy 1989;86:65.

38. Coren S. The Intelligence of Dogs. New York: Free Press, 1994.

39. Rollin BE. The Unheeded Cry: Animal Consciousness, Animal Pain, and Science. Oxford: Oxford University Press, 1990.

40. Melzack R, Casey K. Sensory, motivational and central control determinants of pain: A new conceptual model. In: Kenshalo DL, ed. The Skin Senses. Springfield: CC Thomas, 1968:443.

41. Schechter NL, Allen DA. Physicians' attitudes toward pain in children. Develop Behav Pediatr 1986;1:350-4.

42. Gonzales JL, Gadish HS. Nurses' decisions in medicating children postoperatively. In: Tyler DC, Krane EJ, eds. Advances in Pain Research and Therapy. New York: Raven Press, 1990:147-55.

43. Bauchner H, May A, Coates E. Use of analgesic agents for invasive medical procedures in pediatric and neonatal intensive care units. J Pediatr 1992;121:647-9.

44. Derbyshire SWG. Comment. Pain 1996;67:210-1.

45. LeDoux JE. Emotion: Clues from the brain. Ann Rev Psychol 1995;46:209-35

46. Dennett DC. Consciousness Explained. New York: Back Bay Books, 1991.

47. Smith RM. Anesthesia for Infants and Children. St Louis: Mosby, 1963.

48. Cunningham Butler N. Infants, pain and what health care professionals should want to know now - an issue of epistemology and ethics. Bioethics 1989;3:181-99.

49. Cunningham N. Moral and ethical issues in clinical practice. In: Anand KJS, McGrath PJ, eds. Neonatal Pain and Distress. Amsterdam: Elsevier, 1993:244-74.

50. Wall PD. Response to editorial by Anand and Craig. Pain 1996;67:209.

51. Merskey H. Response to editorial: New perspectives on the definition of pain. Pain 1996;67:209.

52. Anand KJS, Craig KD. Reply to Letters to the Editor from Merskey \& Wall. Pain 1996;67:210.

53. Cunningham N. Letter to the Editor: Comment on Derbyshire [Pain 1996;67:210-1]. Pain. (In press)

54. Engel GL. 'Psychogenic' pain and the pain-prone patient. Am J Med 1959;26:899-918.

55. Meinhart NT, McCaffery M. Pain: A Nursing Approach to Assessment and Analysis. Norwalk: Appleton-Century-Crofts, 1983.

56. Craig KD. The facial expression of pain: Better than a thousand words? Am Pain Soc J 1992;1:153-62.

57. Maurer D, Maurer C. The World of the Newborn. New York: Basic Books Inc, 1988:35,128.

58. Bauer PJ. What do infants recall of their lives. Am Psychol 1996;51:29-41.

59. Taddio A, Goldbach M, Ipp M, Stevens B, Koren G. Effect of neonatal circumcision on pain responses during vaccination in boys. Lancet 1995;345:291-2.

60. Grunau RVE, Whitfield MF, Petrie JH, Fryer EL. Early pain experience, child temperament and family characteristics as precursors of somatization: A prospective study of preterm and fullterm children. Pain 1994;56:353-9.

61. Johnston CC, Stevens B. Experience in a neonatal intensive care unit affects pain response. Pediatrics 1996;98:105-13. 


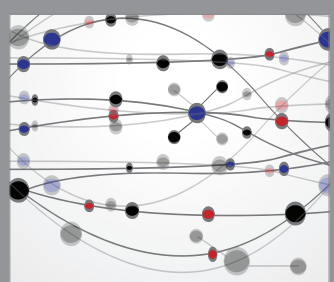

The Scientific World Journal




Gastroenterology Research and Practice

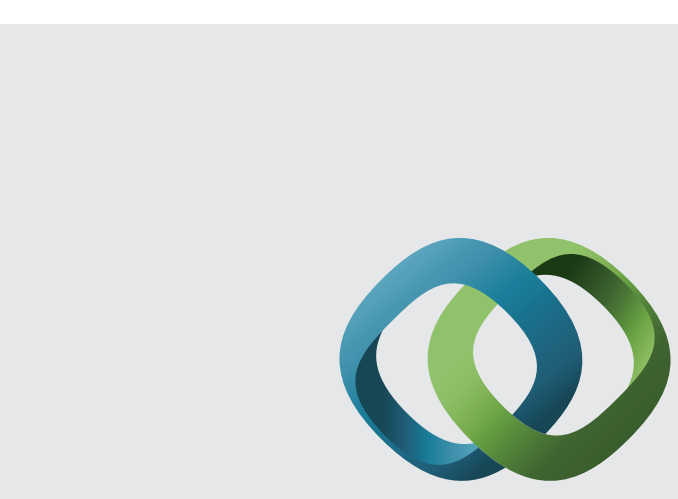

\section{Hindawi}

Submit your manuscripts at

http://www.hindawi.com
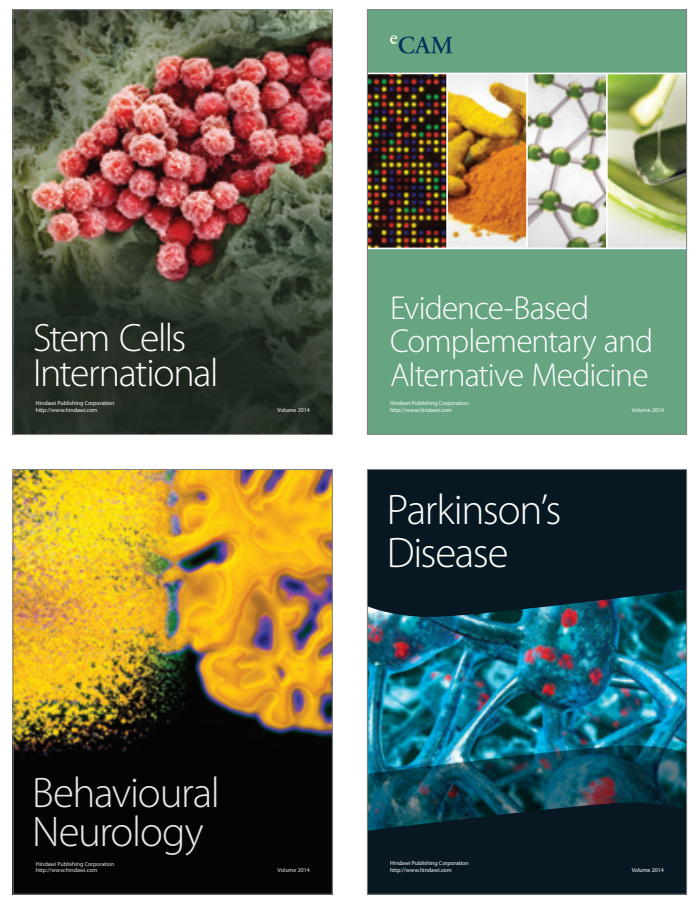
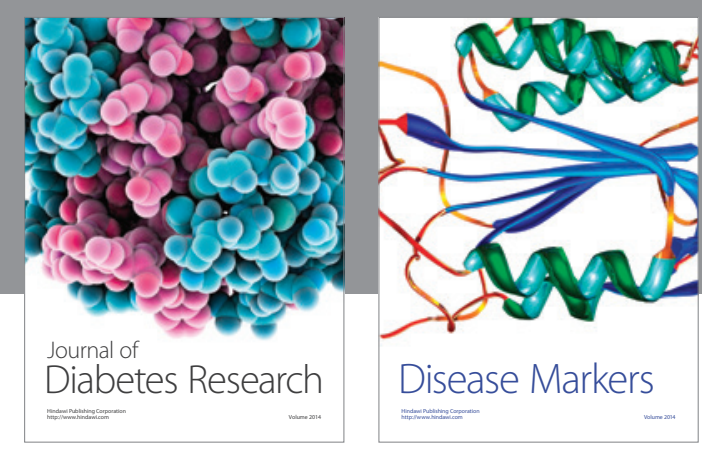

Disease Markers
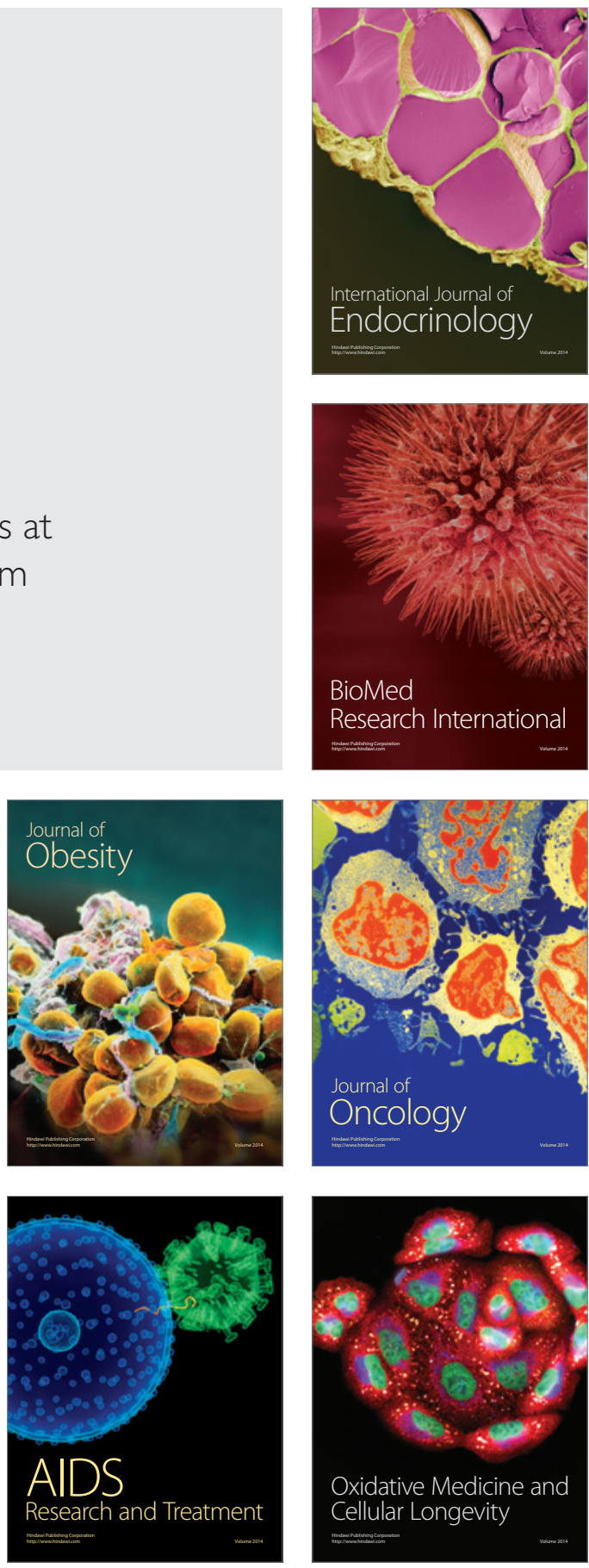